Sergio Endress G.*

\title{
Derecho Presupuestario Chileno: notas sobre sus actores, procedimiento y principios en la Constitución
}

\section{Introducción $^{1}$}

Chile presenta en esta materia un débil estudio dogmático ${ }^{2}$, lo que a su vez incide en la exigua y poco sistemática normativa que contiene la Constitución de 1980. La regulación legal en cambio es extensa y técnicamente muy desarrollada, y se contiene en el Decreto Ley No $1.263^{3}$, denominado Decreto Ley Orgánico de Administración Financiera del Estado. Atendido la materia de nuestro trabajo, aludiremos a estas normas en notas.

El constituyente chileno de 1980 se preocupó más de establecer la preeminencia del Ejecutivo en la definición y proposición del presupuesto ${ }^{4}$, sobre todo en desmedro del Congreso, ${ }^{5}$ que de fijar los principios a que debe someterse esta importante regulación financiera. ${ }^{6}$

* Abogado, Magister en Derecho por la Universidad de Chile y Profesor de Derecho Tributario, Universidad de Chile.
Agradezco especialmente los útiles comentarios y sugerencias de la Profesora de Derecho Administrativo Gladys Camacho C. y del Profesor de Derecho Constitucional Augusto Quintana B., ambos de la Universidad de Chile, pero naturalmente, los errores que pudieran observarse son de mi exclusiva responsabilidad. Sus comentarios a sendress@eioabogados.cl

Mario Verdugo M, Emilio Pfeffer U. y Humberto Nogueira A., Derecho Constitucional, Segunda edición actualizada, Editorial Jurídica de Chile, 1999, tomo II, página 192, sólo alude a algunas normas constitucionales.

Publicado en el Diario Oficial el 28 de noviembre de 1975.

Fruto de una larga evolución constitucional que refiere J. Precht P., op.cit., página 785. Como el autor señala "La Constitución de 1980 culmina este proceso en que la repartición de competencias en materia de Hacienda Pública es radicada con clara preeminencia del Ejecutivo sobre el Parlamento, especialmente en los artículos (hoy) 65 y 67.", op. cit., página 788. El autor señala esta preeminencia como "principio de competencia y su repartición entre el Ejecutivo y el Parlamento en materias de Hacienda Pública”.

5 Exactamente al contrario de lo que sucede en Argentina, como nos señala Horacio Corti "Todas las decisiones fundamentales relativas a las actividad financiera están en manos del Congreso,...", Derecho Constitucional Presupuestario, Editorial Lexis Nexis, Argentina, 2007, página 181.

6 "En 1925 los constituyentes no dieron normas específicas para el derecho financiero del Estado mismo, de modo que los marcos jurídico-financieros de las demás instituciones (personas jurídicas de Derecho Público) deben señalarse respecto de cada una por la ley correspondiente." Alejandro Silva Bascuñan, Tratado de Derecho Constitucional, tomo III, Editorial Jurídica de Chile, 1963, página 308 y agrega "La reforma de 1943 afirmó el predominio del Presidente de la República sobre el Congreso en el orden financiero al aumentar el campo de exclusividad de aquél en cuanto iniciativa de las principales leyes de tal naturaleza y establecer un recurso 
En la definición de las normas presupuestarias intervienen, como actores principales, el Presidente de la República y el Congreso Nacional, conforme expondremos más adelante. En la ejecución del presupuesto y su control interviene también la Contraloría General de la República. ${ }^{7}$

El procedimiento asegura la aprobación del presupuesto, aún en caso de renuencia legislativa.

Los principios del derecho presupuestario, están delineados implícitamente en el texto constitucional. La ley señala que "El sistema de administración financiera del Estado comprende un conjunto de procesos administrativos que permiten la obtención de recursos y su aplicación a la concreción de los logros de los objetivos del Estado. La Administración financiera incluye, fundamentalmente, los procesos presupuestarios, de contabilidad y de administración de fondos." ${ }^{8}$ Para la definición del presupuesto del sector público, debemos acudir a la ley que señala que éste "consiste en una estimación financiera de los ingresos y gastos de este sector para un año dado, compatibilizando los recursos disponibles con el logro de metas y objetivos previamente establecidos".

A continuación examinaremos los tópicos propuestos.

extraordinario en caso de emergencia económica (arts., 21, 45 y 72, No 10).”, ibídem.

Sus funciones de acuerdo al artículo 98 de la CPR, son: "ejercer el control de la legalidad de los actos de la Administración; fiscalizar el ingreso y la inversión de los fondos del Fisco, de las municipalidades y de los demás organismos y servicios que determinen las leyes; examinar y juzgar las cuentas de las personas que tengan a su cargo bienes de esas entidades; llevar la contabilidad general de la Nación, y desempeñar las demás funciones que le encomiende la ley orgánica constitucional respectiva.". Y el Tribunal Constitucional, como nos seńala el siguiente considerando:" 10) A esta enumeración de preceptos constitucionales relacionados con el requerimiento, debe agregarse el artículo 82 que consagra la competencia de este Tribunal Constitucional para resolver los siguientes conflictos de constitucionalidad que puedan afectar a la Ley de Presupuestos: a.- Resolver las cuestiones sobre constitucionalidad que se susciten durante la tramitación de la ley. b.- Resolver los reclamos en caso que el Presidente de la República no promulgue la Ley de Presupuestos cuando debe hacerlo, promulgue un texto diverso o dicte un decreto inconstitucional. c.- Resolver sobre la constitucionalidad de los decretos supremos dictados en el ejercicio de la potestad reglamentaria del Presidente de la República, cuando ellos se refieran a materias que pudieren estar reservadas a la ley por mandato del artículo 60.” Rol o 254, de 26 de abril de 1997.

8 Art. $1^{\circ}$, DL No 1.263, de 28.11.1975. El Decreto Supremo de Hacienda, No 1.256, de 28 de diciembre de 1990, contiene una definición conceptos presupuestarios, tales como glosa, partida, subpartida, capítulo, programa, etc.

$9 \quad$ Art. 11 del DL No 1.263.El Tribunal Constitucional citando a José Luis Cea, señala: Considerando 220. "Que, la Ley de Presupuestos es una ley marco y, por tanto, corresponde al organismo administrativo detallar su ejecución. En este orden de ideas resulta útil recordar la opinión del profesor José Luis Cea Egańa que estima que "la Ley de Presupuestos no es más que un ejemplo particular de aquella configuración global del dominio máximo legal, es decir, que a ella corresponde establecer las bases del régimen presupuestario del sector público, entregando a la potestad reglamentaria la particularización y ejecución del presupuesto nacional. Dicho en otras palabras, la Ley de Presupuestos es una normativa típicamente autorizatoria, en términos generales o básicos, de un marco que contempla los lineamientos fundamentales de la política de ingresos y gastos del Estado para el ańo calendario, cuya aplicación queda entregada al Jefe de Estado";" Rol № 254, de veintiséis de abril de mil novecientos noventa y siete. 


\section{Los actores del Presupuesto}

\section{1. Presidente de la República}

El Presidente de la República es elegido en elecciones directas ${ }^{10}$, abiertas y secretas por 4 ańos no reelegibles ${ }^{11}$ y es el Jefe de Estado, correspondiéndole el gobierno y administración del Estado. ${ }^{12} 13$

La Constitución radica fundamentalmente la potestad financiera en el Presidente de la República. Su intervención se produce en la génesis y definición del mismo presupuesto, conforme a la obligación central que le asigna la carta magna, al señalar que es atribución especial del Presidente "cuidar de la recaudación de las rentas públicas y decretar su inversión con arreglo a la ley." ${ }^{14}$ En el mismo sentido y más ampliamente, el artículo 65, inciso segundo señala que "Corresponderá al Presidente de la República la iniciativa exclusiva de los proyectos de ley que tengan relación (....) con la administración financiera o presupuestaria del Estado, incluyendo las modificaciones de la Ley de Presupuestos (...)" . $^{15}$

La iniciativa exclusiva le está entregada en los ingresos, pues a él corresponde al imponer tributos, determinando su forma, proporcionalidad y progresión ${ }^{16}$; comprometer la responsabilidad financiera del Estado y contratar empréstitos ${ }^{17}$ y en la estimación de rendimientos de los recursos de la misma Ley de Presupuestos. ${ }^{18}$

En materia de egresos, le queda reservada la iniciativa para la supresión, reducción, condonación o exención de tributos; ${ }^{19}$ la condonación, reducción o modificación de las cargas financieras de cualquier naturaleza a favor del Fisco; ${ }^{20}$ la creación de nuevos servicios públicos ${ }^{21}$ y la creación, concesión, aumento y modificación de remu-

Art. 26 CPR. Salvo que se indique otra cosa, las referencias a artículos se deben entender realizadas a la Constitución Política de la República de Chile (CPR), actualizada al 30 de Junio de 2009.

Art. 25 CPR.

Art. 24 CPR

13 Respecto del tema, sentencia de 20 de septiembre de 1989 , rol № 78 , seńala que esta potestad está sujeta a la constitución y es distinta de la ostentada por el Banco Central, como organismo autónomo: citado por Constitución Política de la República de Chile, Concordancias, Antecedentes y Jurisprudencia, por Emilio Pfeffer Urquiaga, Editorial Jurídica Conosur, 1999, página 332.

14 Art. 32, $\mathrm{N}^{\circ} 20 \mathrm{CPR}$

15 Sobre el cálculo de entradas, el artículo 17 del DL No 1263 y sobre el presupuestos de gastos el artículo 19 del mismo cuerpo legal.

16 Art. $65 \mathrm{~N}^{\circ} 1 \mathrm{CPR}$.

17 Art. $65 \mathrm{~N}^{\circ} 3 \mathrm{CPR}$. La exigencia de ley no es aplicable al Banco Central, órgano constitucional autónomo, técnico, con patrimonio propio, que por regla general no puede realizar préstamos, garantizar instituciones financieras públicas ni adquirir documentos por emitidos por el Estado, sus organismos y empresas, conforme a los artículos 63 № 7 y 8 , incisos segundos; artículos 108 y 109 de la CPR.

18 Art. 67 No 3 CPR.

19 Art. $65 \mathrm{~N}^{\circ} 1$ de la CPR. Es inconstitucional el artículo que indica la fuente de recursos, pero no cuenta con el patrocinio del Ejecutivo: sentencia del Tribunal Constitucional (en adelante TC), 12 de agosto de 1996, rol No 242, citado por Pfeffer, op. cit., página 470.

20 Art. $65 \mathrm{~N}^{\circ} 3 \mathrm{CPR}$.

21 Art. 65 inciso $2^{\circ}$ y 32 No 2 CPR. 
neraciones, emolumentos y beneficios en favor de funcionarios de la Administración Pública. ${ }^{22}$

El Presidente de la República, puede decretar pagos no autorizados por la ley, conforme a norma constitucional expresa y específica, en casos de urgencia constitucional. Se trata de necesidades impostergables fundadas en una calamidad pública, agresión exterior, conmoción interna, grave daño o peligro para la seguridad nacional o el agotamiento de recursos destinados a mantener servicios que no puedan paralizarse sin serio perjuicio para el país. ${ }^{23}$ El monto anual de los giros por estas causas no puede exceder el $2 \%$ de los gastos anuales presupuestados, y la contravención de los límites indicados impone la responsabilidad solidaria y personal de los funcionarios públicos que autoricen o den curso a dichos gastos, incluidos los Ministros de Estado. ${ }^{24}$

El artículo 28 del DL No 1.263 permite al Ejecutivo ordenar pagos “excediéndose de las sumas consultadas en los rubros correspondientes", para el cumplimiento de sentencias, devolución de impuestos, cubrir la deuda pública y gastos de previsión social. Todo lo cual debe financiarse con reasignaciones presupuestarias o mayores ingresos.

La Contraloría General de la República no dará curso a los decretos de gastos que excedan el límite señalado en la Constitución, en caso alguno. ${ }^{25} 26$

\subsection{Congreso Nacional}

El Congreso Nacional se compone de dos ramas: la Cámara de Diputados y el Senado. ${ }^{27}$ La primera está integrada por 120 miembros $^{28}$ y el Senado por 38 Miembros.

Humberto Nogueira alude a la intervención parlamentaria en el Derecho Comparado calificándola como la "función financiera" del Congreso, que actúa "autorizando la recaudación de ingresos y la realización de gastos, como también analiza y examina la manera en que se ejecuta el presupuesto, llegando a poder modificar las tendencias programáticas de un Gobierno, al no aprobarle los recursos necesarios para realizar determinados aspectos de su programa" ${ }^{29}$

22 Art. 65 No 4 CPR.

23 Art. 32 No 20 CPR.

24 Incorporado a la constitución de 1925 , en el artículo 72 № 10 por la reforma constitucional contenida en la ley No 7.727 de 23 de noviembre de 1943, y cuyo origen fija A. Silva Bascuńan, en la dictación de decretos de insistencia, por medio de los cuales se ordenaban pagos no autorizados por ninguna en ley en emergencias, Op. cit., página 332. Véase en extenso en las páginas 332 a 339 del texto recién citado.

25 Art. 99 CPR.

26 Sin mención constitucional se encuentran la Dirección de Presupuestos, que es el "organismo técnico encargado de proponer la asignación de recursos financieros del Estado”, conforme al artículo 15, DL No 1.263 y el Servicio de Tesorerías, al cual el mismo texto indicado le encarga "La función recaudadora de todos los ingresos del Sector Público...salvo aquellos que constituyan entradas propias de los servicios.” Art. 30 CPR.

27 Art. 46 CPR.

28 Art. 47 CPR.

29 Mario Verdugo M., Emilio Pfeffer U. y Humberto Nogueira A., Derecho Constitucional, Segunda edición actualizada, Editorial Jurídica de Chile, 1999, tomo II, página 125. 
En Chile, desconfiando de la intervención del Congreso en los presupuestos, el artículo 67 establece que la estimación del rendimiento de los ingresos corresponde exclusivamente al Presidente, previo informe de los organismos técnicos respectivos, ${ }^{30}$ y que el Congreso Nacional no podrá aumentar ni disminuir la estimación de estos ingresos. ${ }^{31}$

En materia de tributos, ya indicamos que su iniciativa exclusiva corresponde al Presidente de la República y la Cámara de Origen para la discusión respectiva es la Cámara de Diputados. 3233

En relación a los gastos, el Congreso no puede aprobar nuevos gastos sin que indique las fuentes de recursos necesarios para atender dicho erogación. ${ }^{34}$ En caso de ser insuficiente

30 Art. 67 inciso $3^{\circ} \mathrm{CPR}$.

Según el Tribunal Constitucional, en relación a la estimación se indica que "Considerando15. Que, sobre el particular, debe precisarse cuál es el régimen de ingresos y egresos que contempla la Ley de Presupuestos en conformidad con las disposiciones constitucionales y legales pertinentes ya invocadas en esta sentencia. Respecto de los ingresos y conforme al inciso segundo del artículo 64 de la Carta Fundamental, la "estimación" corresponde exclusivamente al Presidente de la República. En concordancia con la norma antes citada, el artículo 11 del Decreto Ley No 1.263, de 1975, preceptúa "El presupuesto del Sector Público consiste en una estimación financiera de los ingresos y gastos de este sector para un ańo dado, compatibilizando los recursos disponibles con el logro de metas y objetivos previamente establecidos.” Más adelante, en su artículo 17 reitera que el cálculo de entradas "debe contener una proyección del rendimiento del sistema de ingresos públicos". No hay pues, aquí, una fijación de los ingresos, sino tan sólo una estimación de los mismos.En cuanto a los gastos, y de acuerdo con el sistema legal, no son ellos propiamente fijados en la Ley de Presupuestos, sino autorizados por ella. El mismo artículo 11 antes citado, expresa que el presupuesto del Sector Público consiste en una estimación financiera de los gastos para este sector para un año dado. Por su parte, el artículo 19 del mismo decreto ley referido dispone que "Los presupuestos de gastos son estimaciones del límite máximo a que pueden alcanzar los egresos".De lo hasta aquí expuesto debe destacarse la importante diferencia que existe entre el concepto de "fijación" usado en el artículo 44, № $4^{\text {o }}$ de la Constitución de 1925 y el de "estimación" que contempla la actual Constitución y al que reiteradamente alude el Decreto Ley No 1.263 tantas veces citado;", Rol № 254, veintiséis de abril de mil novecientos noventa y siete.

31 Art. 67 inciso $2^{\circ} \mathrm{CPR}$.

32 El art. 65, inciso $2^{\circ}$ señala "Las leyes sobre tributos de cualquier naturaleza sean, sobre los presupuestos de la Administración Pública y sobre reclutamiento, sólo pueden tener origen en la Cámara de Diputados."

33 Art. 67, inciso $4^{\circ} \mathrm{CPR}$. Conforme al artículo 109, inciso 20 de la CPR, "Ningún gasto público o préstamo podrá financiarse con créditos directos o indirectos del Banco Central." salvo guerra exterior o peligro de ella. Ya en la Constitución de 1925, art. 44 No 4. Señala A. Silva B. que "El origen de esta norma fue una indicación de Mr. Kemmerer que exigía terminantemente que la ley siempre creara la fuente de ingreso, aspecto en el cual se modificó haciendo posible que por lo menos se indique esa fuente, porque, como expreso el Sr., Alessandri "puede suceder que exista un sobrante de fondos y entonces se toma para hacer el nuevo gasto"”, op. cit., página 332.

34 Relativas al traslado de sede legislativa y los gastos que pudiera irrogar, el Tribunal Constitucional indica en los considerandos $6^{\circ}$ a $12^{\circ}$, que se transcriben que " 6 . Que, el proyecto de ley en examen, por las motivaciones ya expuestas, es generador de gastos actualmente no considerados, ya que ellos corresponderían a las exigencias del traslado del Congreso Nacional de su actual sede a la ciudad de Santiago, lo que indiscutiblemente es un hecho nuevo, no previsto hasta este momento; $7^{\circ}$. Que, de acuerdo con la ya transcrita norma del artículo 64 de la Constitución Política, para que el Congreso Nacional pueda pronunciarse sobre un gasto no previsto debe, "al mismo tiempo", esto es, en el mismo acto de su aprobación, "indicar" las fuentes de recursos necesarios para atenderlo; $8^{\circ}$. Que, de conformidad con el artículo 19, No 20, inciso tercero, de la Constitución Política "Los tributos que se recauden, cualquiera que sea su naturaleza, ingresarán al patrimonio de la Nación y no podrán estar afectos a un destino determinado", disposición ésta que obliga a excluir la posibilidad de que la indicación de fuentes de recursos para atender el nuevo gasto generado pueda corresponder al producto de una exacción tributaria; $9^{\circ}$. Que, de consiguiente, la indicación que obligadamente debe acompañar a la generación de un gasto no previsto, sólo puede vincularse a los recursos generales de la Nación, cuyo uso y aplicación están llamados a ser previstos en la formación y aprobación del presupuesto nacional; $10^{\circ}$. Que, el proyecto de ley de que se trata, cuyas 
tal origen de fondos, el Presidente deberá reducir proporcionalmente todos los gastos cualquiera sea su naturaleza, previo informe favorable de la institución a través de la cual se recaude el nuevo ingreso (art. 67, letra f). ${ }^{35}$ El Congreso puede solamente disminuir, aceptar o rechazar gastos, préstamos, servicios, empleos, emolumentos, beneficios y demás iniciativas que proponga el Presidente de la República. ${ }^{36} 3738$

Finalmente, en la participación del Congreso, cabe agregar la existencia de acuerdos políticos logrados entre el Ejecutivo y sectores políticos representados en el Congreso, con el objeto de obtener su apoyo al proyecto de presupuesto, que establecen compromisos no vinculantes para Gobierno destinados a realizar estudios, análisis y proponer planes destinados a fortalecer la eficiencia y rentabilidad social de los proyectos financiados por el presupuesto. ${ }^{39}$

La Constitución indica que por norma general aplicable a todo proyecto de ley, el debate legislativo deber ser concentrado y excluyente de intervenciones parlamentarias misceláneas, estableciendo que durante la tramitación de él, que "en ningún caso se

consecuencias fácticas ya han sido precisadas, no contempla en su texto indicación de especie alguna con respecto a las fuentes del financiamiento de los gastos que demandarán los hechos con los cuales debería materializarse su cumplimiento, ya que sólo se limita a consignar una nueva sede y un nuevo lugar para las sesiones del Congreso Nacional, agregando que sus actuales instalaciones deberán ser destinadas a otras entidades, dentro de los sesenta días siguientes a la publicación de la ley, todo lo cual, otorga a las disposiciones del proyecto una aplicación inmediata o, a lo más, dentro del breve plazo que seńala; $11^{\circ}$. Que, por todas las razones ya indicadas, mal podría entenderse que las consecuencias económicas del proyecto materia de las cuestiones de constitucionalidad no comprometan o comprometerían la administración presupuestaria del Estado, ya que, de una u otra manera, sería en el presupuesto nacional donde debería preverse la atención de los gastos que desencadenaría el referido traslado; $12^{\circ}$. Que, de tal manera y acorde con todo lo consignado precedentemente, forzoso se hace concluir que el artículo único del proyecto de ley que motiva este requerimiento adolece de inconstitucionalidad porque infringe los artículos 62, en sus incisos tercero y final, y 64, en su inciso cuarto, de la Carta Fundamental, por no indicarse en él un financiamiento que demostrare que sus consecuencias resultarían ajenas a la administración presupuestaria del Estado, lo que lo hace, consiguientemente, entrar en el ámbito de tal administración sin la iniciativa constitucionalmente reservada al Presidente de la República, ni indicar fuente alguna de recursos para atender los no previstos gastos que originaría;" Rol No 242, de 12 de agosto de 1996.

35 Art. 65, inciso final CPR. Cea Egaña señala que "Por vez primera se aplicó el art. 64 de la nueva constitución (actual art. 67), con excepción de su inciso final, en la ley No 18.073, publicada en el Diario Oficial el $1^{\circ} \mathrm{de}$ diciembre de 1981, que contiene el Presupuesto de la Nación para 1982.”, José Luis Cea Egaña, ob. cit. en cita al pie No 88, op. cit., página 176.

36 Un tema pendiente técnicamente, ha sido planteado por el economista Ronald Fischer, de la U. de Chile al señalar que respecto de las concesiones "sus costos no quedan reflejados bien en la contabilidad fiscal" y agrega "Desde un punto de vista político, ese es uno de los atractivos de las concesiones, ya que permiten gastar en infraestructura usando pocos recursos del presupuesto anual. Esta ficción contable tiene la ventaja adicional de limitar la supervisión de gastos del Congreso. El problema -agrega el autor- es que el país pierde la flexibilidad para ajustar el gasto de ser necesario, ya que los pagos a los concesionarios no pueden interrumpirse por una crisis." en el artículo de opinión: "No más concesiones (por ahora)", del martes 23 de junio de 2009, en el diario La Segunda, página 20 .

37 En el mismo sentido, respecto de la Constitución de 1925, A. Silva B., señala que esta ley "presenta más bien los rasgos de una autorización anual", atendido el marco estrecho en que el Congreso puede moverse. op.cit., página 327.

38 En materia de gastos variables, el artículo 44 No 4 establecía la posibilidad de modificar los gastos variables, pero solo a iniciativa del Presidente para su aumento.

39 Representan sin duda un importante instrumento de colaboración legislativa entre partidos y grupos políticos representados en el Congreso y el Ejecutivo, con objeto de mejorar la calidad de las políticas públicas: así, Protocolo de 17 de Noviembre de 2008 y Protocolo Adicional de 25 de noviembre de 2008. 
admitirán las (adiciones o correcciones) que no tengan relación directa con las ideas matrices o fundamentales del proyecto.” ${ }^{40} 41$

\section{El procedimiento del presupuesto}

En general, "los presupuestos de la Administración Pública" deben tener por Cámara de origen exclusivamente la Cámara de Diputados. ${ }^{42}$

El Presidente de la República posee la iniciativa exclusiva para proponer el proyecto de ley de Presupuesto, ${ }^{43}$ y debe hacerlo con al menos con tres meses de anterioridad a la fecha en que debe empezar a regir (esto es, el 1 de enero de cada año). ${ }^{44}$

La ley de presupuesto no se encuentra sujeta a ningún quórum especial en su aprobación. $^{45}$

40 Art. 69 CPR. Sobre su alcance sentencia del Tribunal Constitucional, 14 de junio de2004, rol o 410, citado por E. Pfeffer U., op. cit., página 131.

41 De acuerdo al Tribunal Constitucional, considerando SEPTIMO.- "Que el requerimiento impugna la citada norma legal por una razón de forma, ya que es producto de una indicación que excede la idea matriz de la Ley de Presupuestos, y por razones de fondo, consistentes éstas en vulnerar derechos garantizados constitucionalmente a los funcionarios públicos, cuales son la libertad de conciencia, el derecho de reunión, la igualdad ante la ley, el respeto de la vida privada y la libertad de opinión." Posteriormente agrega el mismo alto Tribunal: "NOVENO.Que habiéndose impugnado primeramente el precepto contenido en la segunda parte del artículo 24 del proyecto de Ley de Presupuestos de 2008 por ser producto de una indicación que excede la idea matriz de esta ley, debe recordarse brevemente qué doctrina ha sustentado este Tribunal sobre la materia.Así, en sentencia reciente de 13 de junio de 2007, Rol $\mathrm{N}^{\circ} 786$, luego de recordar en el considerando $16^{\circ}$ "Que, de conformidad con lo que dispone el artículo 69, inciso primero, de la Constitución, los proyectos de ley pueden ser adicionados o corregidos en los trámites que corresponda, tanto en la Cámara de Diputados como en el Senado, siempre que tales adiciones o correcciones tengan relación directa con sus ideas matrices o fundamentales", añade que "la jurisprudencia de este Tribunal ha precisado que "la voz "indicación", referida a un proyecto de ley, comprende, para la técnica legislativa, toda proposición tendiente a corregir o adicionar un proyecto durante la etapa de su discusión y aprobación" (Sentencias Rol N 259 , considerando $16^{\circ}$, y Rol No 719, considerando 21 ${ }^{\circ}$ ), y que "Congruente con lo expresado, el artículo 24, inciso primero, de la Ley $\mathrm{N}^{\circ} 18.918$, Orgánica Constitucional del Congreso Nacional, precisa que "sólo serán admitidas las indicaciones que digan relación directa con las ideas matrices o fundamentales del proyecto". Como es sabido y de acuerdo a lo establecido en el artículo 23, inciso tercero, de la misma Ley $\mathrm{N}^{\circ} 18.918$, "se considerarán como ideas matrices o fundamentales de un proyecto aquellas contenidas en el mensaje o moción, según corresponda", razón por la que "las indicaciones que tienen relación directa con las mismas son las que guardan con las primeras no sólo una vinculación inmediata sino que, además, sustantiva" (Sentencia Rol N ${ }^{\circ} 786$, considerando $17^{\circ}$ );" y finalmente, resuelve que "DECIMOSEGUNDO.- Que, como se aprecia, no hay obstáculo para que en la ley anual de presupuestos se incluyan normas sobre materias relativas a su ejecución o a la administración financiera del Estado,..”, Rol No 1.005-2007, de 24 de diciembre de 2007. Hay fallo de minoría.

42 Art. 65 inciso $2^{\circ}$ CPR. En los mismos términos en la Constitución de 1925, art. 45, inciso $4^{\circ}$

43 Art. 65.3 CPR. El Mensaje Presidencial No 829-356, de 29 de septiembre de 2008, contenía el Proyecto de la Ley de Presupuestos de 2009.

44 Art. 67 inciso $3^{\circ}$ CPR. En la Constitución de 1925, eran cuatro meses de antelación, conforme al artículo 44 No 4 de la misma carta magna.

45 Respecto del aumento en la partida presupuestaria de una empresa pública, se discutió si aplicaba el quórum calificado que para dichas actividades requiere la Constitución: Considerando SEXTO.- Que, de los considerandos precedentes es forzoso concluir que no ha habido violación al artículo 19, № 21, de la Carta Fundamental, con el proyecto de ley en análisis, puesto que cuando en el Presupuesto de la Nación se contempla una partida para que el servicio público Corporación de Fomento de la Producción reciba una suma de dinero destinada 
La ley No 18.918, Orgánica Constitucional del Congreso Nacional, señala:"El proyecto de Ley de Presupuestos será informado exclusivamente por una comisión especial, que se integrará con el mismo número de diputados y de senadores que establezcan las normas reglamentarias que acuerden las Cámaras. Formarán parte de ella, en todo caso, los miembros de sus respectivas comisiones de hacienda. La comisión será presidida por el senador que ella elija de entre sus miembros y deberá quedar constituida antes del término de la legislatura ordinaria.

"Esta comisión especial fijará en cada oportunidad sus normas de procedimiento y formará de su seno las subcomisiones que necesite para el estudio de las diversas partidas del proyecto sin sujeción en ellas a la paridad de que trata el inciso anterior."

Y el artículo 24, de la misma ley, expresa que "En la tramitación de proyectos de ley los miembros del Congreso Nacional no podrán formular indicación que afecte en ninguna forma materias cuya iniciativa corresponda exclusivamente al Presidente de la República, ni siquiera para el mero efecto de ponerlas en su conocimiento."

El inciso segundo del artículo 36 dispone "El proyecto de Ley de Presupuestos aprobado por el Congreso Nacional podrá ser observado por el Presidente de la República si desaprueba una o más de sus disposiciones o cantidades. Sin embargo, la parte no observada regirá como Ley de Presupuestos del año fiscal para el cual fue dictada a partir del $1^{\circ}$ de enero del año respectivo." ${ }^{46}$

Finalmente, el artículo 26 señala que las normas de este artículo y de los artículos 27, 28 y 29 no se aplicarán a la tramitación del proyecto de Ley de Presupuestos, el que deberá ser despachado en los plazos establecidos en la Constitución Política, con la preferencia que determinen los reglamentos de las Cámaras.

Por su parte el Reglamento de la Cámara de Diputados, se refiere al tema en los artículos 173 a 182. El artículo 180, inciso primero, señala: "La aprobación general del Proyecto de Ley de Presupuestos, importa por sí sola la aprobación de todos los gastos fijos, entendiéndose por tales los que deban su origen a leyes especiales o generales de efectos permanentes."

Como sabemos, el proyecto presentado por el Presidente rige como el presupuesto nacional, si el Congreso no lo despacha dentro de los sesenta días posteriores a la presentación del mismo (art. 67 inciso $\left.1^{\circ} \mathrm{CPR}\right)$. Esta norma, se encuentra inspirada sin duda en el trágico episodio histórico que, formalmente, desencadenó la revolución de 1891, en la cual el Presidente José Manuel Balmaceda en ejercicio, dio por aprobado

exclusivamente a aumentar el capital accionario de una sociedad anónima, de la cual es su principal accionista, no está el Estado generando una nueva actividad empresarial ni participando en ella ya que la empresa beneficiaria de este aumento, ENACAR S.A., mantiene su misma actividad y objeto social, por lo que no resulta aplicable el quórum calificado para la aprobación de la ley que así lo autorice;” Rol № 249, de 4 de noviembre de 1996.

46 El artículo 53 de la Ley No 18.918, citada, establece: "La Ley de Presupuestos de la Nación deberá consultar anualmente los recursos necesarios para el funcionamiento del Congreso Nacional, sujetándose a la clasificación presupuestaria común para el sector público". Otras normas pueden consultarse en el Reglamento del Senado, especialmente en sus artículos 28, 44, 187 y 207 a 211. 
el presupuesto del año anterior ante la renuencia del Congreso a prestar su aprobación al presentado en esa oportunidad. ${ }^{47}$

Como se observa, la enfática asignación al Presidente de la iniciativa de proyectos de ley para ingresos y gastos, y la regulada participación del Congreso para aceptarlos o rechazarlos, configura claramente la preeminencia del Poder Ejecutivo en la marcha económica de la Administración.

\section{Los Principios del Presupuesto}

\subsection{Principio de legalidad}

\subsubsection{Introducción}

Conforme al artículo $6^{\circ}$ de la carta constitucional, "Los órganos del Estado deben someter su acción a la Constitución y a las normas dictadas conforme a ella, y garantizar el orden institucional de la República." Y el artículo $7^{\circ}$ señala que "Los órganos del Estado actúan válidamente previa investidura regular de sus integrantes, dentro de su competencia y en la forma que prescriba la ley.

Ninguna magistratura, ninguna persona ni grupo de personas pueden atribuirse, ni aun a pretexto de circunstancias extraordinarias, otra autoridad o derechos que los que expresamente se les hayan conferido en virtud de la Constitución o las leyes.

Todo acto en contravención a este artículo es nulo y originará las responsabilidades y sanciones que la ley señale."

A propósito del requerimiento de 12 senadores, relativo a diversas modificaciones presupuestarias realizadas por el Ejecutivo, ${ }^{48}$ sin presunta habilitación legal, el Tribunal Constitucional, en su sentencia de veintiséis de abril de mil novecientos noventa y siete, piedra basal del Derecho Presupuestario Chileno, rol No 254, considerandos 18 y 19 señala:

"18․ Que, el principio de legalidad aplicado a la Ley de Presupuestos requiere de una interpretación constitucional flexible, racional y lógica ya que este instrumento, aunque formalmente es una ley, reúne características que le dan una categoría especial

47 Como nos dice Alejandro Silva Bascuñan, op. cit., página 315 y 316, "La Carta de 1833, disponía que "las contribuciones se decretan por el tiempo de dieciocho meses..." (art. 37 No 3 ) y agregaba "Se distinguía, por lo tanto, la legislación permanente, que determinaba el respectivo tributo, de la autorización periódica, que permitía cobrarlo, de modo que, sin ésta, el Ejecutivo quedaba impedido de recaudarlo." Y precisa "llegó el 10 de enero de 1891, sin que el presupuesto para este ańo fuera aprobado por las Cámaras, y, como el Presidente Balmaceda dictó un decreto ordenando regir el presupuesto del ańo precedente, ello fue origen inmediato de la revolución.", ibídem, página 322 .

48 Tales como, la Autorización de gastos no aprobados por el Congreso Nacional; el aumento del monto de gastos determinados aprobados por el Congreso Nacional por una cantidad inferior; la modificación de la estructura del Presupuesto creando subtítulos de gastos sin la aprobación del Congreso Nacional y el incremento de los montos de gastos limitados en las glosas presupuestarias que contemplan las leyes respectivas. 
en el ordenamiento jurídico. Es, en definitiva, la herramienta con que cuenta el Estado para satisfacer gran parte de las necesidades públicas.

La diversidad de situaciones que pueden presentarse en la ejecución de la Ley de Presupuestos imposibilitan una previsión total por parte del legislador. En efecto, lo complejo y dinámico no puede regularse íntegramente con anticipación, ni puede tampoco su normativa reducirse a esquemas interpretativos apriorísticos.

En esta contingencia, el otorgamiento al Ejecutivo de facultades de ejecución resulta inevitable para el buen funcionamiento de la acción estatal.

Si no se reconociere al órgano administrativo la posibilidad de acción directa, la Ley de Presupuestos quedaría congelada y sin operatividad. Con razón se sostiene en la doctrina de que el Ejecutivo es el órgano estatal encargado de instrumentar y efectivizar esta ley;"

"19․ Que, en esta línea de argumentación, el Presidente de la República está habilitado para efectuar, vía decreto, determinadas adecuaciones al Presupuesto Nacional y -aún más- se encuentra facultado por la Constitución y la ley para ordenar mayores gastos que los contemplados por la Ley de Presupuestos.

Esto significa que el principio constitucional de legalidad del gasto público debe ser concebido en términos flexibles o relativos, o no rígidos o absolutos, porque es la propia Constitución la que habilita al legislador para obrar así, concretamente, en el artículo 32, No 22."

Y agrega en el mismo fallo, " $24^{\circ}$. Que, el análisis de las normas que regulan el presupuesto nos permite concluir:

A) Que el Presupuesto General de la Nación es materia de ley, encontrándose así consagrado a su respecto el principio de reserva legal. Sin embargo, esto no puede llevar a desconocer que atendida su propia naturaleza, dicho principio recibe una aplicación atenuada y flexibilizada;

B) Que, por su naturaleza, la Ley de Presupuestos dura un año y, por lo tanto, a su vencimiento, deberá impulsarse nuevamente el mecanismo para la dictación de la próxima;

C) Que la reserva de ley, en materia presupuestaria, está complementada por las normas legales citadas en esta sentencia, que autorizan el uso de la potestad reglamentaria para colaborar en la aplicación concreta de su normativa para que ella logre su plena eficacia, $y$

D) Que la ley remite al ejercicio de la potestad reglamentaria, la operación de la Ley de Presupuestos, con lo cual se produce la trilogía Constitución, ley y decreto;"

El Decreto Ley No 1.263 refuerza la legalidad del presupuesto en los incisos $2^{\circ}$ y $3^{\circ}$ del artículo 25, al establecer que solo por ley puede autorizarse el incremento de las sumas globales de gasto, previa habilitación de la misma ley de presupuesto, así como 
el traspaso de fondos entre Ministerios; el traspaso entre las diferentes partidas del presupuesto; los aportes a las empresas del Estado y la concesión de aporte fiscal a las Municipalidades. Otras modificaciones presupuestarias, pueden realizarse por decreto del Ministro de Hacienda. ${ }^{49}$

Del principio de legalidad y su relación con otras normas constitucionales que veremos a continuación, se colige su necesidad para establecer tributos, comprometer el crédito público, realizar la enajenación o cesión de bienes públicos.

\subsubsection{Los tributos}

La Constitución al entregarle al Presidente de la República la iniciativa exclusiva para establecer tributo ${ }^{50} \mathrm{y}$ establecer que dichas iniciativas requieren de ley, ${ }^{51}$ guarda armonía con el mandato del artículo 19 № 20, que señala que la Constitución asegura a todas las personas, "La igual repartición de los tributos en proporción a las rentas o en la progresión o forma que fije la ley, y la igual repartición de las demás cargas públicas."

\subsubsection{Responsabilidad Financiera Estatal}

El principio de legalidad se expresa como exigencia general en el art. Art. 63 No 8 , que precisa la necesidad de ley para la autorizar "la celebración de cualquier clase de operaciones que puedan comprometer en forma directa o indirecta el crédito o la responsabilidad financiera del Estado, sus organismos y de las municipalidades."

\subsubsection{Préstamos}

En relación a los préstamos o empréstitos, los que autoricen a endeudarse al Estado, sus organismos o las Municipalidades, son materias de ley (art. 63 No 7). ${ }^{52}$ La fuente para el servicio de tales deudas debe indicarse en la misma ley y el destino del préstamo debe ser un proyecto específico. La contratación de préstamos que excedan el periodo presidencial requiere una ley de quórum calificado..$^{53}$

Según el artículo 26 de la CPR en concordancia con el art. ículo 70 del DL 1.263.

Art. 65, inciso $4^{\circ} \mathrm{CPR}$.

Art. 63 No 14 CPR. Respecto del tema, la sentencia del Tribunal Constitucional de 26 de abril de 1997, rol Na 254, citada por Pfeffer, op. cit., en la página 469.

52 En la Constitución de 1925, artículo 44 No 2, respecto de la cual señala A. Silva B., página 313: "Se ha precisado, en mejor forma, el precepto de 1833 que prescribía ley para "contraer deudas, reconocer las contraídas hasta el día y designar fondos con qué cubrirlas.". Según el artículo 39, del DL No 1.263, "Se entiende por crédito público la capacidad que tiene el Estado para contraer obligaciones internas o externas a través de operaciones tendientes a la obtención de recursos."

53 Art. 63, No7 CPR. 


\subsubsection{Enajenación o concesión}

Asimismo, la enajenación, arriendo o concesión de bienes del Estado o de Municipalidades, también es materia de ley. ${ }^{54}$

3.1.6. El control de ingresos, inversión y del límite establecido en la Constitución está entregado a la Contraloría General de la República, ${ }^{55}$ a través del control de legalidad de las actos de la administración referidos a los mismos. ${ }^{56} 57$

3.1.7. En relación a los gastos, las Tesorerías del Estado no podrán efectuar ningún pago sino en virtud de un decreto o resolución expedida por autoridad competente, en que se exprese la ley o la parte del presupuesto que autorice aquel gasto. Los pagos se efectuarán considerando, además, el orden cronológico establecido en ella y previa refrendación presupuestaria del documento que ordene el pago. ${ }^{58}$

54 Art. 63 No 10 CPR. Alejandro Silva Bascuńan, nos señala al respecto, que esta norma fue introducida en la Constitución de 1925, con la siguiente redacción "sólo por ley se puede autorizar la enajenación de bienes del Estado o de las Municipalidades, o su arrendamiento o concesión por más de veinte años" (art. 44 № 3)”, op., cit., página 312. De acuerdo al Tribunal Constitucional, Considerando 19."Que luego y en consecuencia, si respecto de los bienes del Estado sólo son materias de ley las que fijen las normas sobre su enajenación, arrendamiento o concesión, conceptos muy claros y precisos y definidos por la ley, y no otras, como su destinación o destino, es decir el que se les consigne, señale o aplique a un fin o efecto determinado, conforme fluye de la apreciación conjunta de la primera acepción del verbo destinar y de la cuarta significación del sustantivo destino dadas por el Diccionario de la Lengua Espańola, al regular el artículo transitorio cuestionado la forma en que el Presidente de la República debe proceder en la destinación del inmueble del Congreso Nacional en Valparaíso, está inmiscuyéndose en una atribución propia y ordinaria del Jefe del Estado y vulnerando, por ende, no sólo el artículo 60 de la Constitución, porque está referido a materia que no es de dominio legal, sino que, además, el artículo $7^{\circ}$ de la misma, por cuanto invade una facultad que es de competencia reservada al Poder Ejecutivo." Rol No 242, 12 de agosto de 1996.

55 Art. $99 \mathrm{CPR}$.

56 Artículos 98 y 99 CPR. En la Constitución de 1925, los incisos referidos fueron agregados al artículo 21 por la Ley No 7.727 de 23 de Noviembre de 1943, que indicaba en su inciso primero: "Un organismo autónomo con el nombre de Contraloría General de la República, fiscalizará el ingreso y la inversión de los fondos del Fisco, de las Municipalidades, de la Beneficencia Pública y de los otros servicios que determinen las leyes; examinará y juzgará las cuentas de las personas que tengan a su cargo bienes de esas entidades, llevará la contabilidad general de la Nación y desempeñará las demás funciones que le encomiende la ley. Se exceptúan de esta disposición las cuentas del Congreso Nacional, que serán juzgadas de acuerdos con sus reglamentos internos." Y su inciso segundo: "La Contraloría no dará curso a los decretos que excedan el límite señalado en el No 10 del art. 72 de la Constitución, y remitirá copia íntegra de los antecedentes a la Cámara de Diputados." todo esto conforme Alejandro Silva Bascuñan, op. cit., página 310.

57 Los títulos Vy VI, del DL 1.263, se titulan "Del sistema de Control Financiero" y "Del sistema de Contabilidad Gubernamental", respectivamente.

58 Art. 100 CPR. La legalidad del gasto es reforzada por Cea cuando afirma "La interpretación sistemática de todas las disposiciones citadas induce a sostener que con ellas ha quedado excluida la posibilidad de que se introduzcan gastos públicos no legislados. Además, puede decirse que ha sido recortada la discrecionalidad administrativa en la materia. En resumen, en su intención o espíritu ha sido terminante el constituyente al exigir decisiones responsables, adoptadas con conocimiento de los costos y beneficios que ellas implican." Tratado de la Constitución de 1980, Jose Luis Cea Egaña, Editorial Jurídica de Chile, 1988, página 176. 


\subsection{Otros principios}

Respecto de los principios presupuestarios y tal como nos indica H. Corti, la certeza exige que la Ley de Presupuesto debe contenerse en una única ley (unicidad), que separadamente (universalidad) contenga un cálculo de todos los gastos de todos los poderes y órganos públicos (generalidad), especificando las cantidades y finalidades de aquellos gastos (especificación cuantitativa y cualitativa). ${ }^{59} 60$

No obstante la mención plural del artículo $65^{61}$, creemos que nuestra carta fundamental también establece la unidad el presupuesto y las exigencias de concentración, eficiencia y planificación que resultan evidente en la administración financiera del Estado.

El Tribunal Constitucional ha señalado que "el Presupuesto es un instrumento de política fiscal que baraja la variable de ingreso y gasto público, lo que explica que éste contenga elementos de periodicidad, discrecionalidad y condicionalidad que lo distinguen de las leyes tradicionales;" 62

En el detalle de estos aspectos seguimos fundamentalmente a Jorge Precht.

\subsubsection{Unidad}

Para Jorge Precht P. "El principio de la unidad tiene en materia de ingresos una consagración constitucional como principio de no afectación de recursos." 6364

Para Alejandro Silva B., en cambio, ${ }^{65}$ respecto de la Constitución de 1925, "Se dudó durante la vigencia de la Constitución de 1833 si la ley anual de Presupuestos debe considerarse como una sola legislación indivisible como un conjunto de tantas leyes diversas como son las autorizaciones que contiene." Posición esta última en que se inscribe Jorge Huneus por él citado, y el mismo A. Silva Bascuńan, pero ahora respecto de la Constitución de $1980,{ }^{66}$ citando en abono a su opinión la sentencia del TC de 26 de abril de 1997 que sostuvo "Que (...) el Presupuesto es un instrumento de po-

\footnotetext{
Horacio Corti, Derecho Constitucional Presupuestario, Lexis Nexis Argentina, 2007, página187.

60 Nos parece sistemáticamente coherente lo que plantea Horacio Corti, que observa que estos principios denominados "principios presupuestarios" por la doctrina y corrientemente abordados como "reglas técnicas (no jurídicas) elaboradas por la ciencia financiera a los fines de elaborar un buen presupuesto." deben ser "reinterpretados como aspectos jurídicos de la reserva legal, lectura que enfatiza la centralidad de la ley y una visión unificada, sistemática y constitucional del asunto.” H. Corti, op. cit., página186 y 187.

${ }^{61}$ El art. 65 inciso $2^{\circ}$ señala "Las leyes sobre tributos de cualquier naturaleza que sean, sobre los presupuestos de la Administración Pública y sobre reclutamiento,..."

62 Sentencia de veintiséis de abril de mil novecientos noventa y siete, rol № 254 , considerando $16^{\circ}$.

63 El artículo 19 No 20, en su inciso segundo seńala "Los tributos que se recauden, cualquiera que sea su naturaleza, ingresarán al patrimonio de la Nación y no podrán estar afectos a un destino determinado.” norma flexibilizada por la reforma de la Ley $\mathrm{N}^{\circ} 19.097$, de 12 de noviembre de 1991.

64 "El presupuesto, la contabilidad y la administración de fondos estarán regidos por normas comunes que aseguren la coordinación y la unidad de la gestión financiera del Estado." art. $3^{\circ}$, inciso $1^{\circ}$, DL No 1263 y agrega el artículo $4^{\circ}$ que todos los ingresos deben reflejarse en un presupuesto y todos los gastos deben estas contemplados en el mismo.

65 Alejandro Silva B, op. cit., página 329.

66 Sobre todo en el tomo V, de su tratado, op. cit., edición del año 2000, página 259.
} 
lítica fiscal que baraja la variable ingreso y gasto público, lo que explica que contenga elementos de periodicidad, discrecionalidad y condicionalidad que lo distinguen de las leyes tradicionales"( Considerando 160 ${ }^{67}$

Se acepta por el texto constitucional que determinados tributos puedan estar afectados a fines propios de la defensa nacional o que aquellos tributos que gravan actividades o bienes que tienen una clara identificación regional o local, puedan ser aplicados al financiamiento de obras de desarrollo por las autoridades respectivas, dentro de los marcos que la ley señale. ${ }^{68}$ En el mismo sentido, el artículo 19 № 22, inciso $2^{\circ}$, primera parte, expresa que "Solo en virtud de una ley, y siempre que no signifique tal discriminación, se podrán autorizar determinados beneficios directos o indirectos a favor de algún sector, actividad o zona geográfica, o establecer gravámenes especiales que afecten a uno u otras." ${ }^{9} 70$

67 Según el Tribunal Constitucional, "23․ Que, son razones históricas, doctrinarias y de texto las que permiten avanzar, como conclusión, que la Ley de Presupuestos se aparta en varios aspectos de las características y objetivos universalmente reconocidos a la ley. En efecto, resulta necesario buscar una explicación a las disposiciones vigentes que autorizan al Poder Administrador para que, mediante el ejercicio de su potestad reglamentaria, pueda efectuar adecuaciones al presupuesto consistentes en traspasos, incrementos, reducciones y otras modificaciones.

La historia nos muestra que la guerra civil de 1891, bajo el gobierno de Balmaceda, se originó en su disputa con el Congreso a raíz de la discusión de la Ley de Presupuestos. Dicha experiencia hizo que el constituyente de 1925 se cuidara de regular en forma exhaustiva el tema. La detenida regulación constitucional, que proviene del texto de 1925, procura evitar así lo que sucedió en el pasado, durante la vigencia de la Constitución de 1833, cuando con el pretexto del despacho de la Ley de Presupuestos el Parlamento presionaba y ejercía influencia sobre el Ejecutivo.

Por su parte, respecto de la Constitución de 1980, debe ponerse de relieve, como lo destaca el profesor don Alejandro Silva Bascuñán que "todo lo relativo al Presupuesto Anual se encuentra sumido en el propósito sustancial de darle unidad de manejo tributario y financiero al sector público, entregando la responsabilidad de su formulación y ejecución al Presidente de la República, como una de las manifestaciones del vigoroso presidencialismo consagrado en la Constitución de 1980"; rol № 254, de veintiséis de abril de mil novecientos noventa y siete.

68 Hasta la fecha, no sabemos de la existencia de este marco legal. En la actualidad, parte importante de la recaudación por el Impuesto Territorial, contenido en la Ley No 17.235 de 16.12.1998, se destina presupuestariamente a las Municipalidades en que se ubican los bienes gravados. Por otro lado, las denominadas Patentes Municipales, gravamen a la actividad profesional, también posee uso y destino local, según el DL No 3.063 de 20 de noviembre de 1996 sobre Rentas Municipales.

Ello, sin perjuicio de la subsistencia de tributos anteriores a la constitución que financian a la Superintendencia de Bancos, conforme al texto de la disposición sexta transitoria que establece que "Sin perjuicio de lo dispuesto en el inciso tercero del № 20 del artículo 19, mantendrán su vigencia las disposiciones legales que hayan establecido tributos de afectación a un destino determinado, mientras no sean expresamente derogadas."

69 De acuerdo al TC "Las diferenciaciones y la ampliación de las preferencias arancelarias a favor de Bolivia, en su carácter de país de menor desarrollo relativo, establecidas para superar las trabas de intercambio económico con ese país, manifiestamente no configuran diferencias arbitrarias, ni discriminación de esa índole en el trato que debe dar el Estado en materia económica, por cuanto aparecen revestidas de razonabilidad y fundamento plausible." Citado por Pfeffer, op. cit., página 239.

70 Respecto de la finalidad de esta norma, según el Tribunal Constitucional: "2. Que la norma constitucional del inciso tercero del numeral 20 del artículo 19, de no afectación de un tributo a un destino determinado, si bien no fue precisada suficientemente en la historia fidedigna de su establecimiento, ha sido la doctrina nacional la que se ha preocupado de dar una explicación del precepto a través de su objetivo, señalando que la norma pretende evitar las dificultades que al manejo de las finanzas públicas generarían un compromiso dado de antemano sobre el destino de los impuestos pues "las necesidades para cuya satisfacción se destinan los recursos son esencialmente variables de año en año (Figueroa Valdés, Juan Eduardo. "Las Garantías Constitucionales del Contribuyente en la Constitución de 1980", página 107)." Es decir, lo que se señala y se desprende de una interpretación armónica de la norma, y es lo que el constituyente ha querido, es que no haya una relación absoluta dependiente y directa entre lo que se recauda por concepto de impuestos y el destino que se da a lo recaudado. Así, el constituyente quiere evitar un vínculo directo y subordinado de un tributo a un gasto determinado;", rol № 219, de 10 de 
Como contenido obligatorio la ley de presupuestos, la Constitución establece que en el caso de franquicias y beneficios indirectos "la estimación del costo de éstos deberá incluirse anualmente en la ley de Presupuestos". ${ }^{71}$

\subsubsection{Anualidad.}

Siempre siguiendo a Jorge Precht, el hoy artículo 67, en relación al artículo $19 \mathrm{~N}^{\circ} 22$, inciso $3^{\circ}$ y 65 , inciso $3^{\circ}$, establece el principio de anualidad, si bien agrega que "salvo el $19 \mathrm{~N}^{\circ} 22$, no se dice expresamente que el presupuesto debe ser anual". ${ }^{72} 73$

\subsubsection{Universalidad.}

Respecto del principio de universalidad, el autor recién citado lo afinca en normas de jerarquía legal establecidas en la Ley Orgánica de la Administración Financiera del Estado, DL No 1.263 de $1975 .{ }^{74}$ Derivándolo del principio de servicialidad del Estado, Jorge Precht identifica el principio de flexibilidad en el art. 1 de la carta magna, en relación a los artículos $3^{\circ}$ y $25^{\circ}$ de la LOC No 18.575 de Bases de la Administración del Estado.

julio de 1995.

71 Art.19 No 22, inciso 20, segunda parte CPR. Jorge Precht identifica además la primera parte del 19 No 22, como el principio de no discrecionalidad administrativa.

72 Página 781. Sobre el tema, a propósito de la Constitución de 1925, Alejandro Silva B., indica que la Ley Orgánica de Presupuestos (ley No 4.520 de 9 de enero de 1929), se dictó dentro de los principios de la Misión Kemmerer, texto la refundido en el Decreto del Ministerio de Hacienda del mismo número, publicado en el Diario Oficial con fecha 23 de julio de 1951, posteriormente DFL No 47 de 4 de diciembre de 1959.

73 Diversas normas del DL No 1.263 señalan que: el ejercicio presupuestario coincidirá con el ańo calendario (art. 12, inciso primero); que existirá un sistema presupuestario compuesto por presupuestos anuales, debidamente coordinados entre si y por un programa financiero de 3 o más años $\left(\operatorname{art.} 5^{\circ}\right.$ y art $\left.9^{\circ}\right)$. Excepcionalmente, estudios de inversión, ejecución de obras y adquisición de materiales (art. 19 bis); compromisos pendientes de pago a fin de ańo (art. 24) e ingresos o gastos aprobados en ejercicios anteriores o en el ejercicio presupuestario (art. 21) pueden incorporarse a un presupuesto posterior o asignarse a más de un presupuesto;

74 (ibídem). 